\title{
Supermarket customers segments stability
}

Received (in revised form): 9th August, 2007

\section{Jaime R.S. Fonseca}

is currently Professor of Statistics/Data Analysis, at Technical University of Lisbon, Institute of Social and Political Sciences - ISCSP. He is the author of two books on Statistics and some technical papers, and has a MSc in Data Analysis and Computation, from Sciences Faculty of Lisbon University. $\mathrm{He}$ is a doctoral student in quantitative methods at the ISCTE-Business School, Department of Quantitative Methods, Lisbon, Portugal.

\section{Margarida G.M.S. Cardoso}

is an assistant professor at the ISCTE Business School. She holds a degree in Mathematics and a Master's degree as well as a PhD in Systems Engineering, from Lisbon Technical University. Her research interests include multivariate statistics and machine learning techniques in marketing research (segmentation and positioning, in particular).

\section{Keywords segmentation, stability, latent segment models, theoretical information criteria}

\begin{abstract}
Stability is a desirable property of a segment structure that has implications in its managerial utility, particularly in what concerns targeting and positioning. The stability of a segment structure is the focus of the present work. We argue that the evaluation of stability should be preceded by an adequate segmentation methodological approach that addresses satisfactorily the issues of selection of segmentation base variables, modelling and determination of an adequate number of segments. We advocate the use of the latent segments model approach (estimation of finite mixtures) and the selection of the best models to be based on the ICL-BIC, CAIC, BIC and L information criteria, which evidence some advantages when dealing with mixed-type variables, commonly used in segmentation. We then address the evaluation of stability. Internal stability is evaluated using split samples procedures and replicating segmentation results. Dynamic stability evaluation relies on analysis of data related to different time periods. An application concerning the segmentation of customers of a supermarket chain illustrates the proposed approach. Two databases related to questionnaires conducted in 2000 and 2003 (with 3,141 and 1,504 observations, respectively) are used. The obtained two-segment structure - Preferential Customers and Occasional Customers - exhibits internal and dynamic nonstability.

Journal of Targeting, Measurement and Analysis for Marketing (2007) 15, 210-221. doi:10.1057/palgrave.jt.5750052
\end{abstract}

\section{INTRODUCTION AND OBJECTIVES}

Since the pioneering work of Smith (1956), market segmentation has become a fundamental concept, both in marketing theory and in practice. ${ }^{1-7}$

\footnotetext{
Correspondence: Jaime R.S. Fonseca, ISCSP - Higher Institute of Socia and Political Sciences,

Technical University of Lisbon,

CAPP - Centre for Public Administration and Policies,

R. Almerindo Lessa,

Lisbon 1300-663, Portugal.

E-mail: jaimefonseca@iscsp.utl.pt
}

Despite some criticised aspects of segmentation ${ }^{1}$, namely about some discrepancy between academic developments and real-world practice (which are still pertinent), market segmentation has long been accepted as a strategic marketing tool to define markets and thereby allocate resources. ${ }^{8}$

Market segmentation is the subdividing of a market into distinct subsets of customers, where any (homogeneous) subset may conceivably be selected as a market target to be reached with a distinct marketing mix. ${ }^{9}$ 
There are several benefits of market segmentation. For example, it provides an improved ability to identify and exploit new market opportunities for commercial benefit, ${ }^{10}$ it is an important area for strategic product development, ${ }^{11}$ it is useful for customer satisfaction measurement, ${ }^{12}$ for understanding and characterising the behaviour of customers. ${ }^{13}$

In order to be valuable to marketing practitioners, the process of market segmentation needs to be able to identify different segments of customers that have uniform and stable responses to a particular set of marketing variables. ${ }^{14}$ Segments' stability, in particular, is a relevant criterion for judging market segmentation ${ }^{15,16}$ since obtaining a segment structure that is stable contributes to increase the practical utility of segmentation, bridging the gap between theory and practice. In fact, a segment structure that is unstable does not enable proper marketing actions, targeting and positioning in particular. This is an important issue in segmentation, which, however, is also a neglected research area. ${ }^{17}$

The goal of this paper is to address the issue of segments' stability. The internal and dynamic stability concepts ${ }^{18}$ are addressed. The methodological approach to segmentation relies on latent segments models (LSMs), ${ }^{19}$ the appropriate modelling process and model selection criteria being discussed.

An application referred to supermarket customers illustrates the discussion. It involves two customers' samples referred to 2000 and 2003, respectively.

The remaining paper is organised as follows. In the next section, we handle the issue of stability. In a further section, we report on LSMs and then perform a segmentation of supermarket's customers and address their stability. Finally, we present some discussion and future work prospects.

\section{THE ISSUE OF STABILITY}

Segmentation theory suggests that groups of customers with similar needs and purchasing behaviours are likely to demonstrate a more homogeneous response to marketing programmes (eg Tsai, C-Y and Chiu, C-C (2004) 'A purchasebased market segmentation methodology', Expert Systems with Applications, Vol. 27, pp. 265-276), the constitution of segments being essential to target marketing. ${ }^{20}$

In order to be able to identify market segments, several problems need to be recognised and dealt with, but the problem of whether identified segments remain stable or are dynamic in nature is largely neglected. ${ }^{21}$

Naturally, segment stability importance varies with the many possible reasons behind segmentation. If segmentation is done for longrange strategic planning, long-term segment stability is important. If, otherwise, segmentation is the base for a tactical decision (eg promotional expenditures allocation), with limited timeframes, stability may not be a critical issue.

There are two main ways of understanding segment stability: internal and dynamic stability. 22,23

Internal stability relates to whether the analysis of independent samples from a given time period yields consistent segment solutions regarding the nature and number of identified segments. This issue can be resolved by split-half procedures. ${ }^{23,24}$ It is recommended to split a sample in half, performing separate analysis of the first and second halves, and comparing the two independent results to see whether each reproduces the other.

The following statement generally illustrates the need to evaluate the internal stability of a segment structure: The most convincing validation technique is a kind of experimental testing which is called cross-validation. Cross-validation consists of systematic replicated clustering for various subsamples of the data and comparing the results. For example, you may be quite confident in your results if you get the same number of clusters along with almost the same centroids having received similar results for many randomly chosen subsamples (Mirkin, ${ }^{25}$ p. 163).

From a managerial perspective, Calantone and Sawyer $^{23}$ also underline the importance of internal stability, because the scope of targeting and positioning decisions requires that they are based on the best available knowledge, and consequently no solution should be accepted without being properly evaluated. ${ }^{26}$ 
Dynamic stability refers to whether identified segments at a given time remain unchanged over time in terms of number, size and profile. ${ }^{16,18}$ Dynamic stability also has targeting and positioning implications as (eg) segment sizes influence the profitability of specific segments and thus prior decisions concerning the choice of which segments to target may turn out to be inexpedient, and the existence of segments with volatile profiles complicates the process of determining the appropriate marketing mix. ${ }^{26}$

Some studies corroborate the importance of segments' stability. For example, in a work that refers to a survey of marketing practices of 32 industrial companies in South Africa, Abratt ${ }^{15}$ identifies the three most commonly used criteria for the constitution of a segment structure: similarity of needs ( 88 per cent of the 32 cases), feasibility of marketing action (75 per cent) and segments' stability over time (50 per cent). Nonstability makes the results difficult to use in developing retail market strategy. ${ }^{16}$

Previous works addressing the issue of stability rely on diverse clustering techniques. Some of them concluded by nonstability of segments, ${ }^{16,23}$ and several studies that are cited by Hoek et al. ${ }^{10}$ and Beane and Ellis ${ }^{27}$ state that segments may change over time and they caution that this should be considered by decision makers relying on cluster analysis studies. Malhotra ${ }^{20}$ suggests that segments can exhibit a high degree of stability.

Because the issue of stability is critical for successful market segmentation, the internal and dynamic stability of a specific segment's structure should be properly evaluated. Naturally, to be able to appropriately identify the true segment structure, one must, first, carefully select the segmentation base variables and conduct the segmentation process, using appropriate techniques.

\section{LATENT SEGMENTS MODELS}

\section{The models}

LSMs (eg Cohen and Ramaswamy ${ }^{19}$ ) are used to identify the latent segments required to explain the associations among a set of observed variables (segmentation base variables) and to allocate observations to these segments. It represents a model-based approach to clustering that connects clustering with classical statistical estimation methods, and assumes that the variables' observations in a sample arise from different segments of unknown proportions.

The use of LSM has become increasingly popular in the marketing literature; some examples are Wedel and Kamakura, ${ }^{22}$ Dillon and Kumar, ${ }^{28}$ and Bhatnagar and Ghose. ${ }^{29}$ This approach to segmentation offers some advantages when compared with other techniques: it identifies market segments and provides unbiased market segment memberships estimates; ${ }^{28}$ it provides means to select the number of segments; ${ }^{30}$ it is able to deal with different measurement levels; ${ }^{31}$ covariates can be included for segment description; ${ }^{32}$ it allocates cases into segments based upon membership probabilities estimated directly from the model, instead of using an ad hoc definition of 'distance' (eg Euclidian distance). ${ }^{33}$

Let $\underline{\gamma}_{i}=\left(\gamma_{i p}\right)$ denote the vector representing the scores of the $i$ th case for the $p$ th segmentation base variable $(i=1, \ldots, n ; p=1, \ldots, P)$.

We consider that the cases on which the attributes are measured arise from a population which we assume to be a mixture of $S$ segments, in proportions $\lambda_{s}$ (mixing proportions or relative segment sizes), $s=1, \ldots, S$. The statistical probability density function of the vector $\underline{y}_{i}$, given that $\underline{y}_{i}$ comes from segment $s$, is represented by $f_{s}\left(\underline{\underline{x}}_{i} \mid \underline{\theta}_{s}\right)$, with $\underline{\theta}_{s}$ representing the vector of unknown parameters associated with the specific pdf chosen.

Then the population density can be represented as a finite mixture of the densities $f_{s}\left(\underline{Y}_{i} \mid \underline{\theta}_{s}\right)$ of $S$ distinct segments, that is,

$$
f\left(\underline{y}_{i} \mid \underline{\psi}\right)=\sum_{s=1}^{S} \lambda_{S} \prod_{p=1}^{P} f_{S}\left(\underline{y}_{i} \mid \underline{\theta}_{S}\right)
$$

where $i=1, \ldots, n, \lambda_{s}>0, \Sigma_{s=1}^{S} \lambda_{s}=1, \psi=\{\underline{\lambda}, \Theta\}$, with $\underline{\lambda}=\left\{\lambda_{1}, \ldots, \lambda_{s-1}\right\}, \Theta=\left\{\underline{\theta}_{1}, \ldots, \underline{\theta}_{s}\right\} . \psi$ is the vector of all unknown parameters.

When dealing with mixture models for nominal, continuous and mixed-type base variables, multinomial, ${ }^{34}$ multivariate normal ${ }^{35}$ and mixed distributional models ${ }^{36}$ can be used, respectively. 
Table 1: Used criteria for assessing number of segments on latent segment models

\begin{tabular}{lll}
\hline Criterion & Definition & Author \\
\hline BIC & $-2 \log L(\hat{\psi})+n_{\psi} \log n$ & Schwarz $^{41}$ \\
ICL-BIC & $\operatorname{BIC}+2 E \hat{N}(S)$ & ${\text { Biernacki et al. }{ }^{42}}_{\text {CAIC }}$ \\
L & $-2 \log L(\hat{\psi})+n_{\psi}(1+\log n)$ & Bozdogan $^{43}$ \\
\hline
\end{tabular}

The LSM estimation problem simultaneously addresses the estimation of distributional parameters and classification of cases into segments, yielding mixing probabilities. The estimation process is typically directed to maximum likelihood using the Expectationmaximisation (EM) algorithm. ${ }^{30,37}$

LSM naturally provides means for constituting a partition by means of assigning each case to the segment with the highest segment-membership probability, that is with $\operatorname{Max}_{s}=1, \ldots, S \hat{\tau}_{i s}$, where

$$
\hat{\tau}_{i s}=\hat{\tau}_{s}\left(\underline{y}_{i} \mid \underline{\psi}^{(k)}\right)=\frac{\hat{\lambda}_{s}^{(k)} f_{s}\left(y_{i} \mid \hat{\theta}_{s}^{(k)}\right)}{\sum_{j=1}^{S} \hat{\lambda}_{j}^{(k)} f^{j}\left(\underline{y}_{i} \mid \hat{\theta}_{j}^{(k)}\right)}
$$

In order to derive meaningful results from clustering, the mixture model must be identifiable, that is, a unique maximum likelihood solution should exist. ${ }^{38}$

\section{Segments structure selection}

A goal of traditional LSM estimation is to determine the smallest number of latent segments $S$ that is sufficient to explain the relationships observed among the variables of segmentation base variables. If the baseline model $(S=1)$ provides a good fit to the data, no LSM is needed because there is no relationship among the variables to be explained; otherwise, a model with $S=2$ segments is then fitted to the data. This process continues by fitting successive LSM to the data, each time adding another dimension by incrementing the number of segments by 1 , until a parsimonious model is found that provides an adequate fit.

In order to select the best number of segments and in an attempt to overcome most of the limitations of likelihood ratio tests (regularity conditions in finite mixtures do not hold), ${ }^{39}$ theoretical information criteria can be used. They assist in determining the adequate value of $S$ based on minimum criteria's values.

The general form of information criteria is $-\log L(\hat{\psi})+C$. The first term is the negative logarithm of the maximum likelihood, which decreases when model complexity increases; the second term or penalty term penalises too complex models and increases with the model number of parameters $\left(n_{\psi}\right)$. Thus, the selected LSM should evidence a good trade-off between good description of the data and the model number of parameters.

A recent work, ${ }^{40}$ based on an empirical analysis, evidences the good performance of BIC, ICL-BIC, CAIC and L criteria when dealing with mixed-type segmentation variables.

Because segmentation problems typically have to deal with mixed-type variables, these criteria (see Table 1) can be advocated as appropriate for LSM selection.

\section{SUPERMARKET CUSTOMERS LATENT SEGMENTS}

\section{Customers' data}

In the present work, we deal with an application concerning the segmentation of supermarket clients. Data are originated from two questionnaires directed to the customers of a supermarket retail chain.

The questionnaire (see Mann and Whitney) ${ }^{45}$ was first conducted in 2000, and a total of 3,141 valid questionnaires were then obtained. A second data set was obtained in 2003 with a total of 1,504 valid questionnaires.

In both situations, questionnaires were administered via personal interviews and were conducted inside the stores of the supermarket chain. 
The measurements fell into three categories: (1) measurements that quantify the customers' preferences and customer/store relationship, such as usage frequency, travel time, transportation (see Table 2); (2) measurements for quantifying the expenditure, amount spent on retail store and proportion of expenditure in retail chain; (3) measurements for proceeding with the customers' socio-economic profile, such as occupation, income, age.

The information collected enables deriving a segment structure based on 2000 and 2003 data sets for the retail chain customers. It also enables analysing the segment structure stability over time, which is a specific aim of the present work.

\section{Segmentation base variables}

The selection of segmentation base variables, defining a set of variables or characteristics used to assign customers to homogeneous segments, is a key issue to successful market segmentation. ${ }^{22}$ Selecting variables to use as a basis for differentiation among consumers is a problem that segmentation studies have to face. ${ }^{16}$

One can consider different types of segmentation base variables. Kotler ${ }^{9}$ considers four segmentation base variable types: geographic, demographic, psychographic and behaviouristic. Wedel and Kamakura ${ }^{22}$ classifies segmentation

Table 2: Segmentation base variables

\begin{tabular}{|c|c|c|}
\hline $\begin{array}{l}\text { Segmentation } \\
\text { base }\end{array}$ & Type & Variables' categories \\
\hline $\begin{array}{l}\text { Amount spent } \\
\text { on retail store }\end{array}$ & Continuous & - \\
\hline $\begin{array}{l}\text { Proportion of } \\
\text { expenditure in } \\
\text { retail chain }\end{array}$ & Continuous & - \\
\hline Transportation & Categorical & $\begin{array}{l}\text { Car, walking, public } \\
\text { transportation, motorcycle }\end{array}$ \\
\hline Travel time & Categorical & $\begin{array}{l}2 \mathrm{~min} \text { walking }(\mathrm{mw}), 2-5 \mathrm{mw} \text {, } \\
5-10 \mathrm{mw} \text {, more than } 10 \mathrm{mw} \text {, } \\
\ldots, \text { more than } 15 \mathrm{~m} \text { by car, } \\
10-15 \mathrm{~m} \text { by car }\end{array}$ \\
\hline Trip origin & Categorical & Home, job, passing by, other \\
\hline $\begin{array}{l}\text { Reasons for } \\
\text { purchasing }\end{array}$ & Categorical & $\begin{array}{l}\text { Home proximity, job } \\
\text { proximity, passing by, low } \\
\text { prices, brand diversity, ..., } \\
\text { doesn't know }\end{array}$ \\
\hline $\begin{array}{l}\text { Usage } \\
\text { frequency }\end{array}$ & Categorical & $\begin{array}{l}\text { Every day, } 2 \text { or } 3 \text { times a } \\
\text { week, once a week, once a } \\
\text { twice a week, ..., occasional }\end{array}$ \\
\hline Visit pattern & Categorical & $\begin{array}{l}\text { During the week, during the } \\
\text { weekend, both situations }\end{array}$ \\
\hline
\end{tabular}

base variables as general and product-specific bases, and as observable or unobservable.

There is no unique correct way of segmenting a market. ${ }^{27}$ Nevertheless, it is well known that the more general the bases used for segmentation, the more stable the derived segments. ${ }^{1}$ Therefore, in the current application, the selection of segmentation base variables relies on general criteria that advocate the use of observable segmentation variables in order to obtain stable segment structures. ${ }^{22}$ In addition, the selection of segmentation base variables also tries to exclude irrelevant variables because they can deteriorate the latent segment solution. ${ }^{6}$

The used segmentation variables are presented in Table 2. They include observable productspecific variables, in accordance with Wedel and Kamakura, ${ }^{22}$ or behaviouristic variables in the sense of Beane and Ennis, ${ }^{27}$ such as amount spent on retail store, proportion of expenditure in the retail chain (the proportion of monthly expenditures which refers to the specific supermarket chain), reasons for purchasing, usage frequency and visit pattern.

\section{Segments' structure}

\section{0 customers' segments}

In order to derive a supermarkets customers' segments structure, an LSM is estimated using the segmentation base variables presented in Table 2 .

Table 3: Information criteria (2000 data set)

\begin{tabular}{lllll}
\hline $\mathbf{S}$ & ICL-BIC & CAIC & BIC & L \\
\hline 1 & 121,048 & 121,098 & 121,048 & 60,490 \\
$\mathbf{2}$ & $\mathbf{1 1 7 , 6 7 4}$ & $\mathbf{1 1 6 , 8 0 6}$ & $\mathbf{1 1 6 , 7 0 5}$ & $\mathbf{5 8 , 5 4 5}$ \\
3 & 115,373 & 114,703 & 114,551 & 57,920 \\
\hline
\end{tabular}

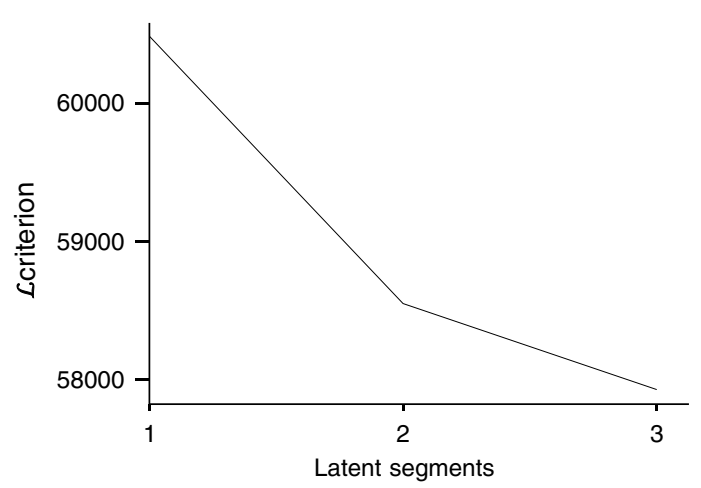

Figure 1: $L$ values for the three estimated models 
Table 4: Segmentation base variables segment's profile (2000 data set)

\begin{tabular}{|c|c|c|c|c|c|}
\hline $\begin{array}{l}\text { Segments } \\
\text { Segments' weights }\end{array}$ & $\begin{array}{l}\text { Segment } 1 \\
(55 \%)\end{array}$ & $\begin{array}{l}\text { Segment } 2 \\
(45 \%)\end{array}$ & $\begin{array}{l}\text { Segments } \\
\text { Segments' weights }\end{array}$ & $\begin{array}{l}\text { Segment } 1 \\
(55 \%)\end{array}$ & $\begin{array}{l}\text { Segment } 2 \\
(45 \%)\end{array}$ \\
\hline Usage frequency & & & Travel time & & \\
\hline Every day & $47 \%$ & $16 \%$ & Missing & $0 \%$ & $0 \%$ \\
\hline 2 or 3 times a week & $38 \%$ & $32 \%$ & 2 minutes walking (mw) & $15 \%$ & $10 \%$ \\
\hline Once a week & $11 \%$ & $21 \%$ & $2-5 \mathrm{mw}$ & $35 \%$ & $21 \%$ \\
\hline Once or twice a week & $2 \%$ & $6 \%$ & $5-10 \mathrm{mw}$ & $19 \%$ & $13 \%$ \\
\hline Once a month & $1 \%$ & $4 \%$ & More than $10 \mathrm{mw}$ & $6 \%$ & $6 \%$ \\
\hline \multirow[t]{2}{*}{ Occasionally } & $1 \%$ & $21 \%$ & Less or equal $5 \mathrm{~m}$ by car & $9 \%$ & $12 \%$ \\
\hline & & & $5-10 \mathrm{~m}$ by car & $4 \%$ & $9 \%$ \\
\hline Reasons for purchasing & & & $10-15 \mathrm{~m}$ by car & $3 \%$ & $8 \%$ \\
\hline Home proximity & $74 \%$ & $43 \%$ & More than $15 \mathrm{~m}$ by car & $9 \%$ & $20 \%$ \\
\hline Job proximity & $7 \%$ & $19 \%$ & & & \\
\hline Passing by & $3 \%$ & $20 \%$ & Visit pattern & & \\
\hline Low prices & $4 \%$ & $4 \%$ & During the week & $20 \%$ & $47 \%$ \\
\hline Brand diversity & $1 \%$ & $1 \%$ & During the weekend & $8 \%$ & $14 \%$ \\
\hline Products diversity & $2 \%$ & $3 \%$ & Both situations & $72 \%$ & $39 \%$ \\
\hline Habit & $2 \%$ & $1 \%$ & & & \\
\hline Product quality & $0 \%$ & $0 \%$ & Coming from & & \\
\hline Fresh products' quality & $0 \%$ & $0 \%$ & Home & $77 \%$ & $54 \%$ \\
\hline Store cleanliness & $0 \%$ & $1 \%$ & Job & $18 \%$ & $34 \%$ \\
\hline Service promptness & $1 \%$ & $1 \%$ & Passing by & $3 \%$ & $11 \%$ \\
\hline Service friendliness & $0 \%$ & $1 \%$ & Other & $1 \%$ & $1 \%$ \\
\hline Promotions & $1 \%$ & $0 \%$ & & & \\
\hline Open hours & $2 \%$ & $3 \%$ & Transportation & & \\
\hline Parking conditions & $1 \%$ & $1 \%$ & Car & $20 \%$ & $33 \%$ \\
\hline Other reasons & $1 \%$ & $1 \%$ & Walking & $74 \%$ & $48 \%$ \\
\hline \multirow[t]{2}{*}{ Doesn't know } & $1 \%$ & $1 \%$ & Public transportation & $6 \%$ & $18 \%$ \\
\hline & & & Motorcycle & $0 \%$ & $1 \%$ \\
\hline \multicolumn{6}{|c|}{ Proportion of expenditure in retail chain } \\
\hline \multirow[t]{2}{*}{ Mean } & 60 & 23 & Amount spent on retail store & & \\
\hline & & & Mean $(\$)$ & $36377^{\star}$ & $11746^{\star \star}$ \\
\hline
\end{tabular}

*181.45€

**58.59€

Results from the maximum likelihood estimation yield alternative solutions, which are evaluated. The information criteria ICL-BIC, CAIC, BIC and L values corresponding to the candidate models are displayed in Table 3.

Taking into account these information criteria values and the corresponding decreasing patterns, a two-segment structure is adopted. Figure 1 illustrates the L's decreasing pattern with an elbow at $S=2$, the selected number of segments. We thus select an LSM with two segments, the segments' weights being 55 and 45 per cent, respectively. The segments' profiles (concerning the used segmentation base variables) are presented in Table 4.

\section{3 custumers' segments}

The results from the maximum likelihood estimation of an LSM using the segmentation variables presented in Table 2 and referred to the 2003 data also yield a two-segment structure.
Table 5: Information criteria (2003 data set)

\begin{tabular}{lllllc}
\hline $\mathbf{S}$ & ICL-BIC & CAIC & BIC & L & $\boldsymbol{E}_{\boldsymbol{s}}$ \\
\hline 1 & 58,472 & 58,513 & 58,472 & 29,208 & - \\
$\mathbf{2}$ & $\mathbf{5 6 , 2 6 3}$ & $\mathbf{5 6 , 3 4 6}$ & $\mathbf{5 6 , 2 6 3}$ & $\mathbf{2 8 , 2 5 8}$ & $\mathbf{1 . 0 0}$ \\
3 & 56,187 & 56,112 & 55,987 & 28,402 & 0.94 \\
\hline
\end{tabular}

Number of observations: 1,504

The ICL-BIC, CAIC, BIC and L values corresponding to the three estimated models are displayed in Table 5 .

All these criteria (L, in particular) suggest the selection of two segments. The corresponding segments' weights are 60 and 40 per cent, respectively. We characterise the two latent segments in Table 6, concerning the used segmentation base variables.

\section{Common segment structure}

As a result of the segments' profiling across the segmentation base variables, on both 2000 and 
Table 6: Segmentation base variables segment's profile (2003 data set)

\begin{tabular}{|c|c|c|c|c|c|}
\hline $\begin{array}{l}\text { Segments } \\
\text { Segments' weights }\end{array}$ & $\begin{array}{l}\text { Segment } 1 \\
(60 \%)\end{array}$ & $\begin{array}{l}\text { Segment } 2 \\
(40 \%)\end{array}$ & $\begin{array}{l}\text { Segments } \\
\text { Segments' weights }\end{array}$ & $\begin{array}{l}\text { Segment } 1 \\
(60 \%)\end{array}$ & $\begin{array}{l}\text { Segment } 2 \\
(40 \%)\end{array}$ \\
\hline Usage frequency & & & Travel time & & \\
\hline Every day & $40 \%$ & $16 \%$ & Missing & $0 \%$ & $7 \%$ \\
\hline 2 or 3 times a week & $35 \%$ & $32 \%$ & 2 minutes walking $(\mathrm{mw})$ & $26 \%$ & $0 \%$ \\
\hline Once a week & $15 \%$ & $21 \%$ & $2-5 \mathrm{mw}$ & $37 \%$ & $0 \%$ \\
\hline Once or twice a week & $1 \%$ & $7 \%$ & $5-10 \mathrm{mw}$ & $26 \%$ & $0 \%$ \\
\hline Once a month & $5 \%$ & $10 \%$ & More than $10 \mathrm{mw}$ & $11 \%$ & $0 \%$ \\
\hline \multirow[t]{2}{*}{ Occasionally } & $5 \%$ & $14 \%$ & Less or equal $5 \mathrm{~m}$ by car & $0 \%$ & $37 \%$ \\
\hline & & & $5-10 \mathrm{~m}$ by car & $0 \%$ & $19 \%$ \\
\hline Reasons for purchasing & & & $10-15 \mathrm{~m}$ by car & $0 \%$ & $19 \%$ \\
\hline $\begin{array}{l}\text { Home proximity } \\
\text { Job proximity }\end{array}$ & $\begin{array}{r}71 \% \\
7 \%\end{array}$ & $\begin{array}{r}51 \% \\
7 \%\end{array}$ & More than $15 \mathrm{~m}$ by car & $0 \%$ & $18 \%$ \\
\hline Passing by & $4 \%$ & $18 \%$ & Visit pattern & & \\
\hline Low prices & $4 \%$ & $4 \%$ & During the week & $26 \%$ & $33 \%$ \\
\hline Brand diversity & $1 \%$ & $2 \%$ & During the weekend & $11 \%$ & $23 \%$ \\
\hline Products diversity & $2 \%$ & $3 \%$ & Both situations & $63 \%$ & $44 \%$ \\
\hline Habit & $4 \%$ & $4 \%$ & & & \\
\hline Product quality & $2 \%$ & $5 \%$ & Coming from & & \\
\hline Fresh products' quality & $1 \%$ & $0 \%$ & Home & $78 \%$ & $59 \%$ \\
\hline Store cleanliness & $0 \%$ & $1 \%$ & Job & $16 \%$ & $28 \%$ \\
\hline Service promptness & $1 \%$ & $2 \%$ & Passing by & $4 \%$ & $9 \%$ \\
\hline Service friendliness & $1 \%$ & $2 \%$ & Other & $2 \%$ & $4 \%$ \\
\hline Promotions & $0 \%$ & $0 \%$ & & & \\
\hline Open hours & $1 \%$ & $0 \%$ & Transportation & & \\
\hline Parking conditions & $0 \%$ & $0 \%$ & Car & $0 \%$ & $81 \%$ \\
\hline Other reasons & $0 \%$ & $0 \%$ & Walking & $100 \%$ & $0 \%$ \\
\hline \multirow[t]{2}{*}{ Doesn't know } & $1 \%$ & $1 \%$ & Public transportation & $0 \%$ & $19 \%$ \\
\hline & & & Motorcycle & $0 \%$ & $0 \%$ \\
\hline \multicolumn{6}{|c|}{ Proportion of expenditure in retail chain } \\
\hline \multirow[t]{2}{*}{ Mean } & 51 & 38 & Amount spent on retail store & & \\
\hline & & & Mean $(€)$ & 304 & 316 \\
\hline
\end{tabular}

2003 data sets, we name Segment 1 as Preferential customers and Segment 2 as Occasional customers.

Preferential customers go often to the retail supermarkets; they live nearby and walk to the super. These customers allocate 60 per cent (51 per cent) of their home monthly expenditures to the retail chain in 2000 (2003), with the amount spent on retail store of $181.45 €,(304 €)$ in 2000 (2003).

Occasional customers also include some customers that go often to the supermarket but they clearly differ from Preferential customers, concerning occasional purchases. Location (home proximity) is an important reason for purchasing for both segments; however, for Occasional customers job proximity is also relevant. This segment also includes more customers who go to the super by car.

In order to further support the identification of Preferential customers and Occasional customers, some socio-demographic characteristics are used for the two segments' profiling (Tables 7 and 8 for 2000 and 2003, respectively).
The socio-demographic segments' profiles (2000 and 2003) are summarised in Table 9.

The 2000 segments' structure is in general accordance with the 2003 corresponding one. This can be seen as a first indicator of segments' stability.

Additional analyses concerning this specific issue are included in the remainder of the paper.

\section{Segments' stability}

\section{Internal stability}

In order to evaluate internal stability of the obtained segments' structure, both the 2000 and 2003 data sets are split into samples of equal size, and clustering analysis using LSM is conducted in both subsamples. ${ }^{6,18}$

For both split-half samples of the 2000 data set, the used information criteria select two segments (Table 10), with relative sizes 56 and 44 per cent for split1, and 54 and 46 per cent for split2 (Table 12). These results are similar to the ones found for the whole 2000 data set. 
Table 7: Socio-demographic segments' profile (2000)

\begin{tabular}{|c|c|c|c|c|c|}
\hline \multicolumn{3}{|l|}{ Segment } & \multicolumn{3}{|l|}{ Segment } \\
\hline & $\begin{array}{l}\text { Preferential } \\
\text { customers }\end{array}$ & $\begin{array}{l}\text { Occasional } \\
\text { customers }\end{array}$ & & $\begin{array}{l}\text { Preferential } \\
\text { customers }\end{array}$ & $\begin{array}{l}\text { Occasional } \\
\text { customers }\end{array}$ \\
\hline Occupation & & & Income & & \\
\hline Profession & 0.132 & 0.173 & Less than ${ }^{*} 80,000 \$$ & 0.061 & 0.052 \\
\hline Employment & 0.762 & 0.755 & $80,000 \$-160,000 \$$ & 0.185 & 0.158 \\
\hline \multirow[t]{2}{*}{ Both } & 0.106 & 0.072 & $161,000 \$-240,000 \$$ & 0.169 & 0.179 \\
\hline & & & $241,000 \$-320,000 \$$ & 0.089 & 0.128 \\
\hline Qualifications & & & $321,000 \$-400,000 \$$ & 0.073 & 0.076 \\
\hline Illiterate/inc. basic schooling & 0.021 & 0.020 & More than $400,000 \$$ & 0.151 & 0.157 \\
\hline Complete basic schooling (4) & 0.238 & 0.176 & Does not answer & 0.274 & 0.249 \\
\hline 6 years basic schooling & 0.094 & 0.092 & & & \\
\hline 9 years schooling - 11th Grade & 0.189 & 0.183 & Life cycle & & \\
\hline Complete secondary schooling year & 0.126 & 0.162 & Single & 0.219 & 0.287 \\
\hline Incomplete higher education & 0.057 & 0.070 & Common-law marriage & 0.070 & 0.100 \\
\hline 3 year degrees & 0.045 & 0.050 & C.-L M. with children & 0.228 & 0.265 \\
\hline $4 / 5$ years degrees & 0.223 & 0.237 & Married/no children & 0.217 & 0.159 \\
\hline \multirow[t]{2}{*}{ Does not answer } & 0.007 & 0.011 & Married/with children & 0.115 & 0.074 \\
\hline & & & Divorced/no children & 0.061 & 0.059 \\
\hline Family & & & Divorced/with children & 0.001 & 0.003 \\
\hline 1 & 0.125 & 0.106 & Widowed/no children & 0.030 & 0.022 \\
\hline 2 & 0.260 & 0.250 & Widowed/with children & 0.006 & 0.005 \\
\hline 3 & 0.267 & 0.291 & & & \\
\hline 4 & 0.226 & 0.250 & Age & & \\
\hline 5 & 0.083 & 0.081 & Less than 25 years & 0.128 & 0.180 \\
\hline \multirow{4}{*}{6 or more } & 0.039 & 0.022 & $25-34$ years & 0.170 & 0.246 \\
\hline & & & $35-44$ years & 0.192 & 0.220 \\
\hline & & & $45-55$ years & 0.225 & 0.182 \\
\hline & & & More than 55 years & 0.285 & 0.172 \\
\hline
\end{tabular}

*399.04€

Table 8: Socio-demographic segments' profile (2003)

\begin{tabular}{|c|c|c|c|c|c|}
\hline \multicolumn{3}{|l|}{ Segment } & \multicolumn{3}{|l|}{ Segment } \\
\hline & $\begin{array}{l}\text { Preferential } \\
\text { customers }\end{array}$ & $\begin{array}{l}\text { Occasional } \\
\text { customers }\end{array}$ & & $\begin{array}{l}\text { Preferential } \\
\text { customers }\end{array}$ & $\begin{array}{l}\text { Occasional } \\
\text { customers }\end{array}$ \\
\hline Occupation & & & Income & & \\
\hline Profession & 0.181 & 0.182 & Less than $400 €$ & 0.069 & 0.025 \\
\hline Employment & 0.784 & 0.782 & $401-798 €$ & 0.163 & 0.122 \\
\hline \multirow[t]{2}{*}{ Both } & 0.035 & 0.036 & $799-1197 €$ & 0.196 & 0.178 \\
\hline & & & $1198-1596 €$ & 0.120 & 0.146 \\
\hline Qualifications & & & $1597-1995 € €$ & 0.059 & 0.102 \\
\hline Illiterate/inc. basic schooling & 0.042 & 0.011 & More than $1996 €$ & 0.078 & 0.153 \\
\hline Complete basic schooling (4) & 0.205 & 0.125 & Does not answer & 0.315 & 0.274 \\
\hline 6 years basic schooling & 0.092 & 0.092 & & & \\
\hline 9 years schooling -11 th Grade & 0.164 & 0.151 & Life cycle & & \\
\hline Complete secondary schooling year & 0.137 & 0.193 & Single & 0.243 & 0.243 \\
\hline Incomplete higher education & 0.088 & 0.068 & $\begin{array}{l}\text { Common-Law } \\
\text { Marriage }\end{array}$ & 0.043 & 0.080 \\
\hline 3 year degrees & 0.044 & 0.045 & C.-L M. with children & 0.059 & 0.092 \\
\hline $4 / 5$ years degrees & 0.190 & 0.283 & Married/no children & 0.066 & 0.117 \\
\hline \multirow{2}{*}{ Does not answer } & 0.038 & 0.032 & Married/with children & 0.288 & 0.278 \\
\hline & & & Divorced/no children & 0.055 & 0.065 \\
\hline Family & & & Divorced/with children & 0.086 & 0.065 \\
\hline 1 & 0.165 & 0.164 & Widowed/no children & 0.072 & 0.032 \\
\hline 2 & 0.242 & 0.225 & Widowed/with children & 0.088 & 0.030 \\
\hline 3 & 0.301 & 0.278 & & & \\
\hline 4 & 0.203 & 0.238 & Age & & \\
\hline 5 & 0.052 & 0.060 & Less than 25 years & 0.189 & 0.175 \\
\hline \multirow[t]{4}{*}{6 or more } & 0.037 & 0.035 & $25-34$ years & 0.169 & 0.260 \\
\hline & & & $35-44$ years & 0.171 & 0.255 \\
\hline & & & $45-55$ years & 0.193 & 0.185 \\
\hline & & & More than 55 years & 0.278 & 0.125 \\
\hline
\end{tabular}


Table 9: Common socio-demographic segments' characteristics (2000 and 2003)

\begin{tabular}{lll}
\hline Variables & Preferential customers (2000 and 2003) & Occasional customers (2000 and 2003) \\
\hline Occupation & Profession & Employment \\
Family & Family with less and family with more individuals (1-3 or 6 and more) & Family with 4 or 5 individuals \\
Education & Customers with less qualifications & Customers with more qualifications \\
Income & Customers with less income & Customers with more income \\
Life cycle & Widowed/no children and Widowed/with children & Common-law marriage and common-law \\
Age & The older customers & marriage with children \\
\hline
\end{tabular}

Table 10: Split-half sample results (2000 data set)

\begin{tabular}{|c|c|c|c|c|c|c|c|c|c|c|}
\hline \multirow[b]{2}{*}{$\mathbf{S}$} & \multicolumn{5}{|c|}{ First split-half sample } & \multicolumn{5}{|c|}{ Second split-half sample } \\
\hline & ICL-BIC & CAIC & BIC & $\mathbf{L}$ & $E_{s}$ & ICL-BIC & CAIC & BIC & $\mathbf{L}$ & $E_{s}$ \\
\hline 1 & 59,374 & 59,422 & 59,374 & 29,654 & - & 62,894 & 62,947 & 62,894 & 31,410 & - \\
\hline 2 & 57,419 & 57,843 & 57,386 & 28,839 & 0.98 & 61,189 & 60,798 & 60,691 & 30,512 & 0.77 \\
\hline 3 & 56,852 & 56,614 & 56,468 & 28,733 & 0.89 & 60,151 & 59,909 & 59,748 & 30,447 & 0.89 \\
\hline
\end{tabular}

Table 11: Slit-half sample results (2003 dataset)

\begin{tabular}{|c|c|c|c|c|c|c|c|c|c|c|}
\hline \multirow[b]{2}{*}{$\mathbf{S}$} & \multicolumn{5}{|c|}{ First split-half sample } & \multicolumn{5}{|c|}{ Second split-half sample } \\
\hline & ICL-BIC & CAIC & BIC & $\mathbf{L}$ & $E_{s}$ & ICL-BIC & CAIC & BIC & $\mathbf{L}$ & $E_{s}$ \\
\hline 1 & 28,677 & 28,718 & 28,677 & 14,311 & - & 29,990 & 30,030 & 29,990 & 14,968 & - \\
\hline 2 & 27,684 & 27,767 & 27,684 & 13,939 & 1.00 & 28,965 & 29,045 & 28,964 & 14,578 & 1.00 \\
\hline 3 & 27,564 & 27,663 & 27,538 & 14,088 & 0.98 & 29,063 & 29,030 & 28,908 & 14,777 & 0.91 \\
\hline
\end{tabular}

Table 12: Summary of segments' structure sizes

\begin{tabular}{|c|c|c|c|c|}
\hline & \multicolumn{2}{|l|}{2000} & \multicolumn{2}{|l|}{2003} \\
\hline & Preferential clients & Occasional clients & Preferential clients & Occasional clients \\
\hline First-split sample & $56 \%(882)$ & $44 \%(693)$ & $61 \%(453)$ & $39 \%(290)$ \\
\hline Second-split sample & $54 \%(846)$ & $46 \%(720)$ & $59 \%(449)$ & $41 \%(312)$ \\
\hline Whole sample & $55 \%(1728)$ & $45 \%(1413)$ & $60 \%(902)$ & $40 \%(602)$ \\
\hline
\end{tabular}

The same procedure is used for both split-half samples of the 2003 data set (results in Table 11). The used information criteria also select two segments, with relative sizes 61 and 39 per cent for split1, and 59 and 41 per cent for split2, (Table 12) results being similar to the ones found for the whole 2003 data set.

Results referred to internal stability evaluation are summarised in Table 12, evidencing good internal stability of the obtained two-segment structure.

Overall, the results suggest that the obtained segment structure - Preferential customers and Occasional customers - evidences good internal stability, the segments being adequately differentiated on segmentation base variables.

\section{Dynamic stability}

As far as dynamic stability is concerned, the two retail customers' segments are compared with respect to their distributions in 2000 and 2003 (see Table 13) and their respective sociodemographic profiles (see Table 14).

To evaluate the segments' size dynamic stability, a chi-square test is used. It enables testing the null hypotheses that the segments' distribution referred to 2000 and 2003 is identical.

Because significant differences are found $\left(\chi^{2}=\right.$ 10.039, $p=0.002)$, the segments' sizes are not stable.

To provide comparisons between the sociodemographic segments' profiles, we run a Mann-Whitney ${ }^{45}$ test and a chi-square test. ${ }^{46}$ Comparisons are referred to usage frequency, reasons 
Table 13: Respondents distribution on the two segments in 2000 and 2003

\begin{tabular}{llll}
\hline Year & $\begin{array}{l}\text { Preferential } \\
\text { customers }\end{array}$ & $\begin{array}{l}\text { Occasional } \\
\text { customers }\end{array}$ & Total \\
\hline 2000 & $1727(55 \%)$ & $1414(45 \%)$ & 3141 \\
2003 & $902(60 \%)$ & $602(40 \%)$ & 1504 \\
Total & 2629 & 2016 & 4645 \\
\hline
\end{tabular}

Table 14: Comparisons between segment's profiles (2000 vs 2003)

\begin{tabular}{|c|c|c|}
\hline Variables & $\begin{array}{l}\text { Preferential } \\
(p \text {-value*) }\end{array}$ & $\begin{array}{l}\text { Occasional } \\
\left(p-\text { value }^{\star \star}\right)\end{array}$ \\
\hline Usage frequency & 0.000 (M.-W.) & 0.740 (M.-W.) \\
\hline Reasons for purchasing & 0.000 (C.-S.) & 0.000 (C.-S.) \\
\hline Travel time & 0.000 (M.-W.) & 0.000 (M.-W.) \\
\hline Visit pattern & 0.000 (C.-S.) & 0.000 (C.-S.) \\
\hline Coming from & 0.001 (C.-S.) & 0.000 (C.-S.) \\
\hline Transportation & 0.000 (C.-S.) & 0.000 (C.-S.) \\
\hline
\end{tabular}

*Preferential customers.

${ }^{\star *}$ Occasional customers.

M.-W., Mann-Whitney test; C.S., chi-square test.

for purchasing, travel time, visit pattern, coming from and transportation distributions in the 2000 and 2003 segments (Tables 7 and 8, respectively).

Results are summarised in Table 14 .

The $p$-value results of Mann-Whitney and chi-square tests allow for concluding that there are significant differences between the 2000 and 2003 segments' profiles, except for usage frequency, referred to the occasional customers' segment. Therefore, the dynamic stability of the obtained segment structure cannot be sustained.

\section{DISCUSSION AND FUTURE WORK}

Segment structure stability has clear implications in the managerial utility of segmentation, because only stable segments can provide the basis for the development of a successful marketing strategy. Stability is necessary, at least for a period long enough for segments' identification, implementation of a marketing strategy and for the strategy to produce results. ${ }^{22}$

Although some authors say that segments are intrinsically unstable over time, ${ }^{27}$ others argue that segment structures can exhibit a high degree of stability. ${ }^{20}$

The focus of the present study is the stability of a segments structure. From a methodological point of view, we argue that using an appropriate segmentation methodology based on appropriate segmentation base variables contributes to identify the true segment structure, a necessary assumption for addressing the problem of stability.

In particular, we underline the importance of conducting an adequate modelling approach and using appropriate criteria for determining the true number of segments.

After having derived a specific segments structure, we emphasise the need to address its internal and dynamic stability. The verification of internal stability contributes to the analyst's confidence in the obtained segmentation results (similar results being obtained for randomly chosen subsamples). The verification of dynamic stability (segments remaining unchanged over time in terms of number, size and profile) relies on comparing results referred to different time periods and has a particular impact on managerial decisions concerning targeting and positioning.

In the present work, we discuss the stability of supermarket customers' segments. Data originate from two similar surveys conducted in 2000 and 2003 and directed to the customers of a supermarket chain.

The selection of segmentation base variables takes into account the fact that observable (product-specific) variables potentially contribute to the constitution of stable segments.

The clustering approach relies on the estimation of an LSM, the advantages of which have been considered in order to identify the true segments' structure. The information criteria used to select the best LSM have a good performance when using mixed-type segmentation base variables, as in the current application.

As a result, a two-segment structure is obtained - Preferential and Occasional customers - which, after being evaluated, shows internal stability. In what concerns dynamic stability, differences were found between segments' sizes (55 and 45 per cent in 2000 and 60 and 40 per cent in 2003, corresponding to Preferential and Occasional customers, respectively), and the segments' profiles also differ significantly between 2000 and 2003. 
These findings are in accordance with those of Hoek et al., ${ }^{10}$ Calantone and Sawyer ${ }^{23}$ and Mols et al., ${ }^{26}$ showing that dynamic stability is very difficult to achieve.

An implication may be that managers have to act in compliance with and think about shortterm strategies, not giving occasion to changes in the segments structure.

Along with this, it is suggested that the segmentation process would be regularly in the time, either to confirm the previous segments' structure or to reveal a new structure and, in accordance, to stimulate new strategies, adequate to a dynamic market.

In the current application, decisions concerning the selection of segmentation base variables were empirically guided. In fact, although there has been an increasing investment concerning the use of LSM in segmentation and of specific criteria for model selection, there still is a gap between theory and practice in what concerns the appropriate choice of segmentation base variables. We think that further research concerning the appropriate selection of segmentation variables for LSM is needed in order to properly identify stable segment structures.

\section{Acknowledgments}

We thank the referees for their many valuable suggestions, which led to a significant improvement of the article.

\section{References}

1 Wind, Y. (1978) 'Issues and advances in segmentation', Journal of Marketing Research, Vol. XV, pp. 317-337.

2 Punj, G. and Stewart, D. W. (1983) 'Cluster analysis in marketing research: Review and suggestions for application', Journal of Marketing Research, Vol. XX (May), pp. 134-148.

3 Grover, R. and Srinivasan, V. (1987) 'A simultaneous approach to market segmentation and market structuring', Journal of Marketing Research, Vol. XXIV, pp. 139-153.

4 Dibb, S. and Stern, P. (1995) 'Questioning the reliability of market segmentation techniques', Omega, International Journal management Science, Vol. 23, No. 6, pp. 625-636.

5 Kim, B. -D., Srinivasan, K. and Wilcox, R. T. (1999) 'Identifying price sensitive consumers: The Relative merits of demographic vs. purchase pattern information', Journal of Retailing, Vol. 75, No. 2, pp. 173-193.

6 Vriens, M. (2001) Market segmentation analytical developments and applications guidlines, Technical Overview Series (Millward Brown IntelliQuest).

7 Fennell, G., Allenby, G. M., Yang, S. and Edwards, Y. (2003) 'The effectiveness of demographic and psychographic variables for explaining brand and product category use', Quantitative Marketing and Economics, Vol. 1, pp. 233-244.

8 Assael, H. and Roscoe, A. M. (1976) 'Approaches to market segmentation analysis', Journal of Marketing, Vol. 40, pp. 67-76.

9 Kotler, P. (1976) 'Marketing Management: Analysis, Planning, and Control', 3rd edn, Prentice-Hall, Inc., Englewood Cliffs, NJ.

10 Hoek, J., Gendall, P. and Esslemont, D. (1996) 'Market segmentation. A search for the Holy Grail?', Journal of Marketing Practice: Applied Marketing Science, Vol. 2, No. 1, pp. 25-34.

11 Westad, F., Hersleth, M. and Lea, P. (2004) 'Strategies for consumer segmentation with applications on preference data', Food Quality and Preference, Vol. 15, pp. 681-687.

12 Wu, J. N., DeSarbo, W. S., Chen, P. J. and Fu, Y.Y. (2006) 'A latent structure factor analytic approach for customer satisfaction measurement', Marketing Letters, Vol. 17, pp. 221-238.

13 Heilman, C. M. and Bowman, D. (2002) 'Segmenting consumers using multiple-category purchase data', International Journal of Research in Marketing, Vol. 19, No. 3, pp. 225-252.

14 Fuller, D., Hanlan, J. and Wilde, S. (2005) 'Market segmentation approaches: Do they benefit destination marketers?', Centre for Enterprise Development and Research, Southern Cross University, Coffs Harbour Campus, Occasional paper No.4.

15 Abratt, R. (1993) 'Market segmentation practices of industrial marketers', Industrial Marketing Management, Vol. 22, pp. 79-84.

16 Lockshin, L. S., Spawton, A. L. and Macintosh, G. (1997) 'Using product, brand and purchasing involvement for retail segmentation', Journal of Retailing and Consumer Services, Vol. 4, No. 3, pp. 171-183.

17 Wright, M. (1996) 'The dubious assumptions of segmentation and targeting', Management Decision, Vol. 34, No. 1, pp. 18-24.

18 Soutar, G. N. and Sweeney, J. (2003) 'Are there cognitive dissonance segments?' Australian Journal of Management, Vol. 28, No. 3, pp. 227-249.

19 Cohen, S. H. and Ramaswamy, V. (1998) 'New tools for market segmentation: An introduction to latent class models', Marketing Research, Vol. 10, pp. 14-21.

20 Malhotra, N.K. (1989) 'Segmenting hospitals for improved management strategy', Journal of Health Care Marketing, Vol. 9, pp. $45-52$.

21 Mitchell, V. -W. and Wilson, D. F. (1998) 'Balancing theory and practice. A reappraisal of business-to-business segmentation', Industrial Marketing Management, Vol. 27, pp. 429-445.

22 Wedel, M. and Kamakura, W. A. (1998) 'Market Segmentation: Concepts and Methodological Foundations', 2nd edn, Kluwer Academic Publishers, Boston.

23 Calantone, R. J. and Sawyer, A. G. (1978) 'The stability of benefit segments', Journal of Marketing Research, Vol. XV, pp. 395-404.

24 Malhotra, N. K. (1996) 'Marketing Research — An Applied Orientation', Prentice-Hall, Upper Saddle River.

25 Mirkin, B. (1996) 'Mathematical Classification and Clustering', Kluwer Academic Publishers, Dordrecht.

26 Mols, N. P., Antvor, H. and Bukh, P. N. D. (1999) 'The stability of benefit segments in the European market for cash management services', Journal of Segmentation in Marketing: Innovations in market identification and targeting, Vol. 3, No. 1, pp. $55-75$.

27 Beane, T. P. and Ennis, D. M. (1987) 'Market-segmentation - A review', European Journal of Marketing, Vol. 21, No. 5, pp. 20-42.

28 Dillon, W. R. and Kumar, A. (1994) 'Latent structure and other mixture models in marketing: An integrative survey and overview, chapter 9', in Bagozi, R.P. (ed), 'Advanced Methods of Marketing Research', Blackwell Publishers, Cambridge, pp. 352-388. 
29 Bhatnagar, A. and Ghose, S. (2004) 'A latent class segmentation analysis of e-shoppers', Journal of Business Research, Vol. 57, pp. $758-767$.

30 McLachlan, G. F. and Peel, D. (2000) 'Finite Mixture Models', 1st edn, John Wiley \& Sons, Inc, p. 419.

31 Vermunt, J. K. and Magidson, J. (2002) 'Latent class cluster analysis', in Hagenaars, J.A. and McCutcheon, A.L. (eds), 'Applied Latent Class Analysis', Cambridge University Press, Cambridge, pp. 89-106.

32 Magidson, J. and Vermunt, J. K. (2003) 'A Nontechnical Introduction to Latent Classe Models', Statistical Innovations, Inc, Tilburg University, Nederlands, p. 15.

33 Bonilla, J. and Huntington, J. (2005) 'Leveraging latent class segmentation to optimize marketing campaigns and sales force implementation', in 2005 PMSA Conference.

34 Hall, P. and Titterington, D. M. (1984) 'Efficient nonparametric estimation of mixture proportions', Journal of the Royal Statistical Society, Series B, Vol. 46, No. 3, pp. 465-473.

35 Basford, K. E. and McLachlan, G. J. (1985) 'Likelihood estimation with normal mixture models', Applied Statistics, Vol. 34, No. 3, pp. 282-289.

36 Hunt, L. A. and Basford, K. E. (1999) 'Fitting a mixture model to three-mode three-way data with categorical and continuous variables', Journal of Classification, Vol. 16, pp. 283-296.

37 Dempster, A. P., Laird, N. M. and Rubin, D. B. (1977) 'Maximum likelihood from incomplete data via EM algorithm', Journal of the Royal Statistics Society, B, Vol. 39, pp. 1-38.

38 Bozdogan, H. (1994) 'Mixture-model cluster analysis using model selection criteria and a new informational measure of complexity', in Bozdogan, H. (ed), 'Proceedings of the First US/Japan Conference on the Frontiers of Statistical Modeling: An Approach, 69-113', Kluwer Academic Publishers, pp. 69-113.

39 Ramaswamy, V., Chaterjee, R. and Cohen, S. H. (1996) 'Joint segmentation on distinct interdependent bases with categorical data', Journal of Marketing Research, Vol. XXXIII, pp. 337-350.

40 Fonseca, J. R. S. and Cardoso, M. G. M. S. (2007) 'Mixturemodel cluster analysis using information theoretical criteria', Intelligent Data Analysis, Vol. 11, pp. 155-173.

41 Schwarz, G. (1978) 'Estimating the dimension of a model', The Annals of Statistics, Vol. 6, No. 2, pp. 461-464.

42 Biernacki, C., Celeux, G. and Govaert, G. (2000) 'Assessing a mixture model for clustering with the integrated completed likelihood', IEEE Transactions on Pattern analysis and Machine Intelligence, Vol. 22, No. 7, pp. 719-725.

43 Bozdogan, H. (1987) 'Model selection and Akaikes's information criterion (AIC): The general theory and its analytical extensions', Psycometrika, Vol. 52, No. 3, pp. 345-370.

44 Figueiredo, M. A. T. and Jain, A. K. (2002) 'Unsupervised learning of finite mixture models', IEEE Transactions on pattern analysis and Machine Intelligence, Vol. 24, No. 3, pp. 1-16.

45 Mann, H. B. and Whitney, D. R. (1947) 'On a test of whether one of two random variables is stochastically larger than the other', The Annals of Mathematical Statistics, Vol. 18, pp. 50-60.

46 Chernoff, H. and Lehmann, E. L. (1954) 'The use of maximum likelihood estimates in X2 tests for goodness of fit', The Annals of Mathematical Statistics, Vol. 25, No. 3, pp. 579-586. 